\title{
Author Correction: The downstream air pollution impacts of the transition from coal to natural gas in the United States
}

\author{
Jennifer A. Burney (D)
}

Correction to: Nature Sustainability https://doi.org/10.1038/s41893-019-0453-5, published online 6 January 2020.

In the version of this Analysis originally published, an aggregation error in the analysis code resulted in a miscalculation of the number of coal-fired units in a given area, which affected the results in two ways. It resulted in overestimating the impact for an individual unit and appeared again when aggregating up to totals. After fixing this error, some of the impacts are no longer statistically significant: specifically, results for mortality are only significant at the more local scale (a unit shutdown within $25 \mathrm{~km}$ of a county, no longer out to $200 \mathrm{~km}$ ), and crop impacts are exclusively corn, as the smaller wheat and soybean results are not statistically significant. Overall, the total human impacts are $\sim 85 \%$ of previous values $(22,600$ versus $\sim 26,600)$, and crop impacts are exclusively corn at $58 \%$ of the previous values. The following sentences were updated to reflect these changes:

In the Abstract, the text 'In total during this period, the shutdown of coal-fired units saved an estimated 26,610 (5\%-95\% confidence intervals (CI), 2,725-49,680) lives and 570 million (249-878 million) bushels of corn, soybeans and wheat in their immediate vicinities; these estimates increase when pollution transport-related spillovers are included' has been updated to:

'In total during this period, the shutdown of coal-fired units saved an estimated 22,563 (5\%-95\% confidence intervals (CI), $1,697-43,429)$ lives and 329 million (169-490 million) bushels of corn in their immediate vicinities; these crop estimates increase when pollution transport-related spillovers are included.'

In the Results section, second paragraph, the text 'Accounting for location- and time-invariant effects lowers this effect to $0.23 \mu \mathrm{g} \mathrm{m}^{-3}$ (Fig. 2c, top) and, although the sign and significance of the impacts is robust, aggregating to the county level and allowing for different overall impact distances results in impact estimates that range between around 0.1 and $0.2 \mu \mathrm{g} \mathrm{m}^{-3}$ per unit shutdown (Fig. $2 \mathrm{c}$, bottom; Supplementary Tables 1-3)' has been updated to:

'Accounting for location- and time-invariant effects lowers this effect to $0.23 \mu \mathrm{g} \mathrm{m}^{-3}$, and normalizing for the average number of units shutdown at a given location and time (1.8) gives a per-unit estimate of $0.13 \mu \mathrm{g} \mathrm{m}^{-3}$ (Fig. 2c, top). Although the sign and significance of the impacts is robust, aggregating to the county level and allowing for different overall impact distances results in impact estimates that range between around 0.025 and $0.05 \mu \mathrm{g} \mathrm{m}^{-3}$ per unit shutdown (Fig. 2c, bottom; Supplementary Tables 1-3).'

In the Results section, third paragraph, the text 'Matching plants to counties using two methods (see Methods) revealed that counties with a coal-fired-unit shutdown in their immediate vicinity (Fig. 2, Supplementary Fig. 4) experienced an average associated 0.9\% $(0.1-1.7 \%)$ reduction in total all-cause mortality rate following a unit decommissioning, which was concentrated in older age groups (Fig. 3a). These counties also benefited from increases in crop yields of 7.2\% (3.3-1.1\%), 6.3\% (2.4-10.2\%) and 4.0\% (-0.3-8.3\%) for corn, soybeans and wheat, respectively.' has been updated to:

'Matching plants to counties using two methods (see Methods) revealed that counties with a coal-fired-unit shutdown in their immediate vicinity (Fig. 2, Supplementary Fig. 4) experienced an average associated $0.18 \%(0.01-0.35 \%)$ reduction in total all-cause mortality rate following each unit decommissioning, which was concentrated in older age groups (Fig. 3a). These counties also benefited from increases in corn yields of $1.1 \%(0.56-1.63 \%)$.'

In the Results section, fourth paragraph, the text 'In total, the shutdown of coal-fired units saved an estimated 26,610 (2,725-49,680) lives and 570 million (249-878 million) bushels of staple crop production in the immediate vicinities of the coal-fired units during this time period. When pollution transport-related spillovers are included out to $200 \mathrm{~km}$ (Fig. $3 \mathrm{e}, \mathrm{f}$ ), these estimates increase to 38,200 lives and 4.8 billion bushels across the affected counties between 2005 and 2016 . The inverse calculation of benefits foregone by not shutting a unit down suggests that coal-fired units remaining online caused 329,417 (34,378-626,776) deaths and the loss of 10.2 billion (4.4-15.8 billion) bushels of crops over the time period (these values are for the $25 \mathrm{~km}$ estimate; both this estimate and the higher $200 \mathrm{~km}$ estimate are shown in Extended Data Fig. 9). For reference, this is roughly equivalent to half of a recent year's production-the United States produced 14.4 billion, 2.3 billion and 4.4 billion bushels of corn, wheat and soy in 2017, respectively, or a total of 21.3 billion bushels $^{37}$ has been updated to:

'In total, the shutdown of coal-fired units saved an estimated 22,563 (16,896-43,428) lives and 329 million (169-490 million) bushels of corn production in the immediate vicinities of the coal-fired units during this time period. When pollution transport-related spillovers are included out to $200 \mathrm{~km}$ (Extended Data Fig. 9), these estimates increase to 1.8 billion (0.9-2.7 billion) bushels across the affected counties between 2005 and 2016. The inverse calculation of benefits foregone by not shutting a unit down suggests that coal-fired units remaining online caused 141,588 (10,647-272,528) deaths and the loss of 2.6 billion $(4.4-15.8$ billion) bushels of crops over the time period (these values are for the $25 \mathrm{~km}$ estimate; both this estimate and the higher $200 \mathrm{~km}$ estimate for corn are shown in Extended Data Fig. 9). For reference, this is roughly equivalent to a fifth of a recent year's production - the United States produced 14.4 billion bushels of corn in $2017^{37}$. 


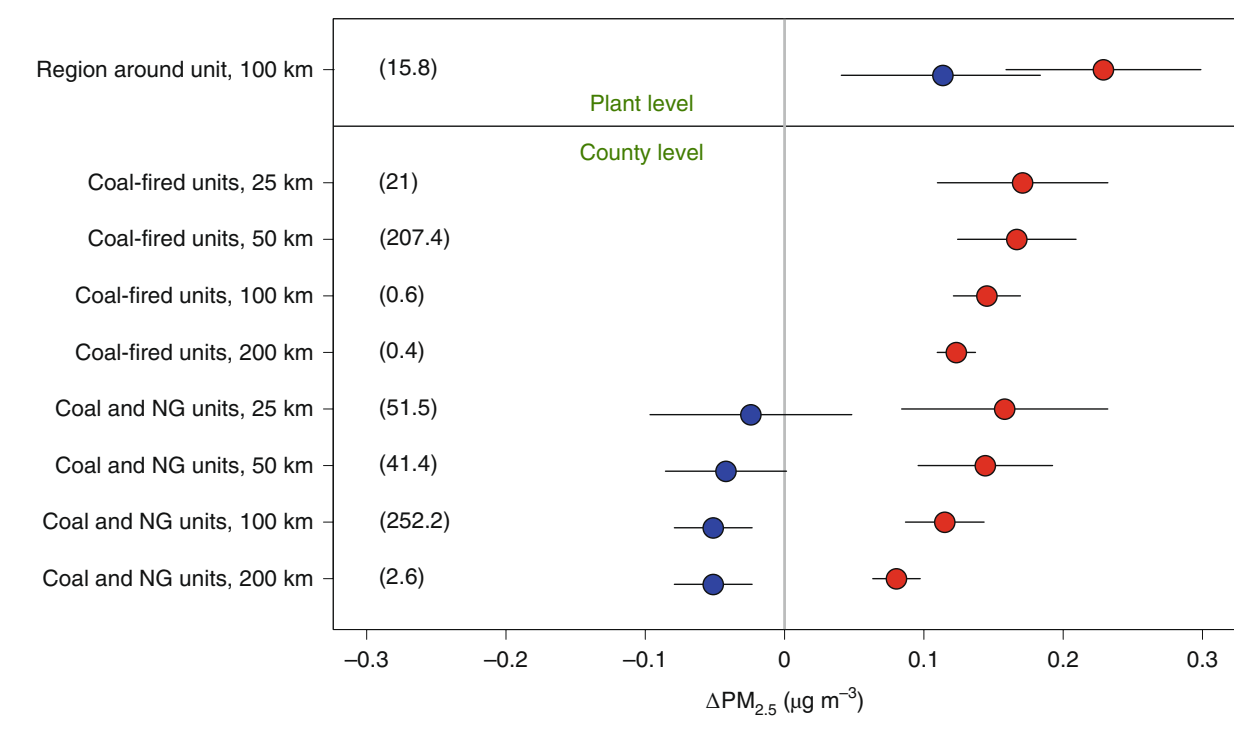

c

Corrected

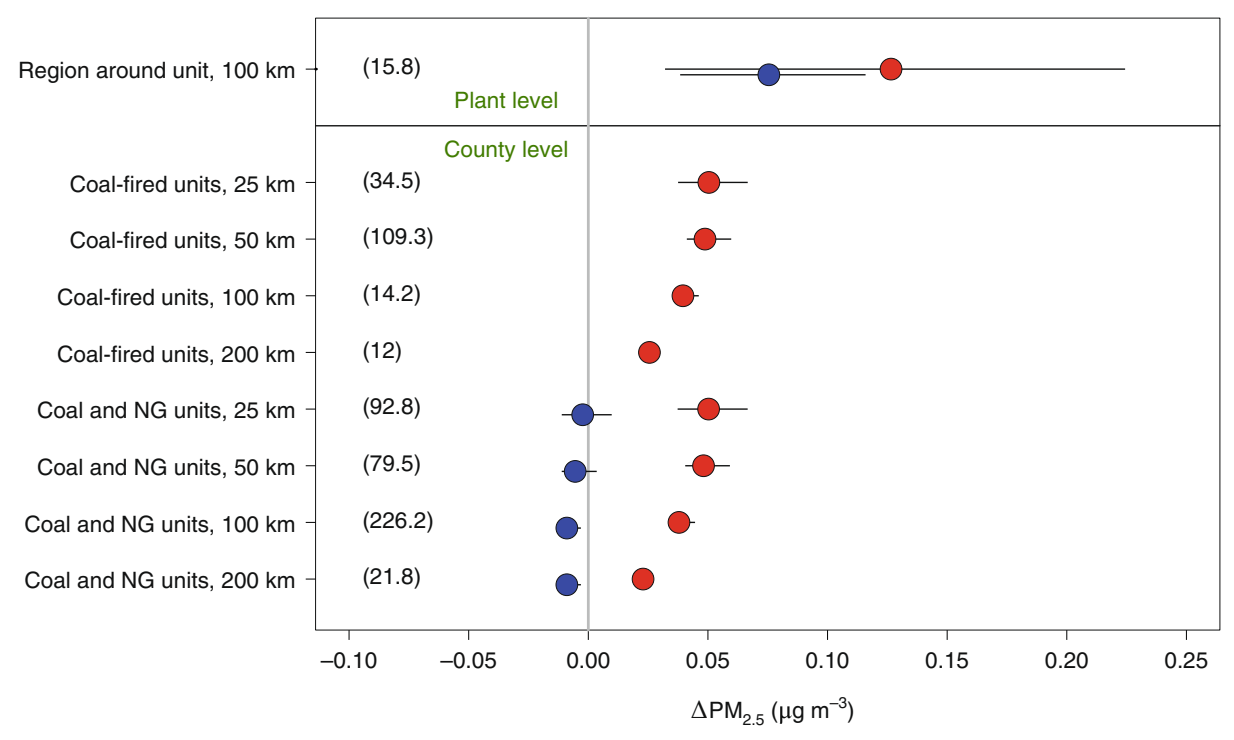

Fig. 2c | Original and Corrected.

Figure $2 \mathrm{c}$ was corrected to reflect the correct unit-specific estimates, and the caption for panel $\mathbf{c}$ has been modified as follows. 'c, Adjusting for temporal dynamics reduces the marginal effect of a shutdown by roughly half (top) and these estimates are similar whether conducting the analysis at the location level or aggregating to counties (bottom)'. has been updated to:

'c, Adjusting for temporal dynamics reduces the marginal effect of a shutdown by roughly half, and normalizing by average number of units shutdown at the same time (1.8) brings the estimate to $0.13 \mu \mathrm{g} \mathrm{m} \mathrm{m}^{-3}$ (top). At the county level, each coal-fired unit within $25 \mathrm{~km}$ is associated with an average county-level change of $0.05 \mu \mathrm{g} \mathrm{m}^{-3}$, with smaller impacts for plants further away (bottom).'

Figure 3 was updated to reflect the correct unit-specific estimates; panels $\mathbf{e}$ and $\mathbf{f}$ were removed since mortality effects out to $200 \mathrm{~km}$ are not statistically significant. (Crop effects, still statistically significant out to $200 \mathrm{~km}$, still appear in Extended Data Fig. 9.) The caption has been modified as follows: 'a-f, Mortality rate (a) and crop yield (b) impacts associated with the decommissioning of coal-fired power units, and the geographical distributions of lives $(\mathbf{c}, \mathbf{e})$ and crops $(\mathbf{d}, \mathbf{f})$ saved. Estimates are shown for three models on the basis of their predictive power for pollution changes shown in Fig. 2. The plant location was used as the unit of analysis and each plant was matched to its county crop and demographic data (circles in a and b). Information was aggregated about all of the plants within a $25 \mathrm{~km}$ (squares in $\mathbf{a}$ and $\mathbf{b}$ ) and $200 \mathrm{~km}$ (diamonds in $\mathbf{a}$ and $\mathbf{b}$ ) radius to the county level to match with county data. Using the more local $25 \mathrm{~km}$ 


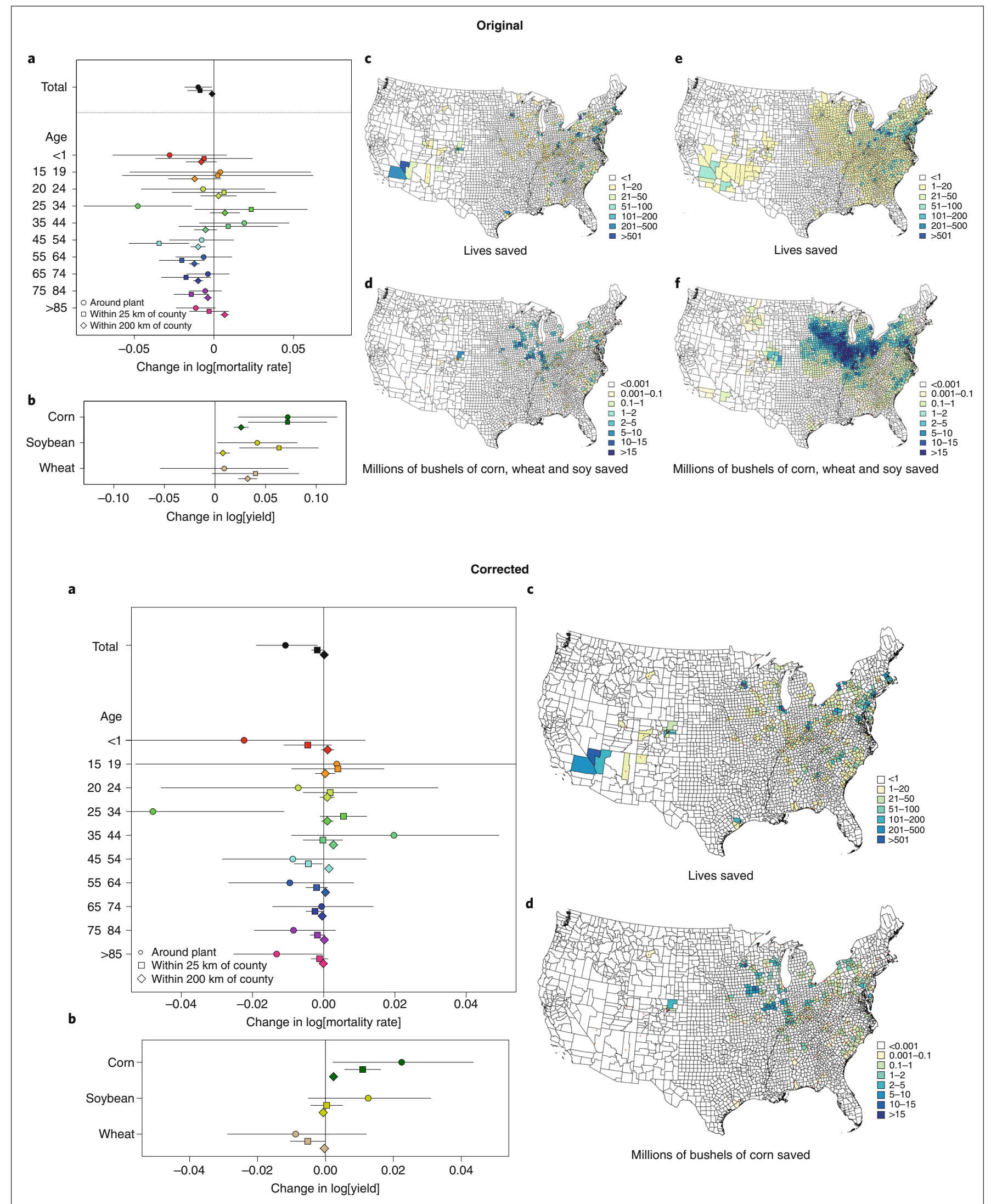

Fig. 3 | Original and Corrected. 
estimate at the county level, the decommissioning of a coal-fired unit is associated with a $0.9 \%$ reduction $(0.1-1.7 \%)$ in overall mortality rate. When broken down by age group, these effects more strongly impact the 45-84 age groups (omitted age groups had insufficient statistics for calculation). Coal-unit shutdowns are also associated with an increase in crop yields of 7.2\% (3.3-11.1\%), 6.3\% (2.4-10.2\%) and $4.0 \%(-0.3-8.3 \%)$ for corn, soybeans and wheat, respectively. All of the analyses include unit and year fixed effects to time-invariant location-specific factors as well as overall temporal shocks that might confound the relationship. The error bars show the 5\%-95\% CI on the basis of s.e. clustered at the location or county level. The distribution of these impacts (central estimate) is shown in $\mathbf{c}$ and $\mathbf{d}$ for $25 \mathrm{~km}$, and in $\mathbf{e}$ and $\mathbf{f}$ for $200 \mathrm{~km}$, bracketing estimates for local effects and larger-scale spillovers. Aggregating the more restricted local $25 \mathrm{~km}$ estimates suggests that the shift in feedstock away from coal saved 26,610 (2,725-49,680) lives and 570 million (249-878 million) bushels of staple crop production. Aggregating the $200 \mathrm{~km}$ impacts raises the central estimates to 38,200 lives and 4.8 billion bushels saved by decommissioning of coal-fired units between 2005 and $2016^{1,37,74}$. has been updated to:

'a-d, Mortality rate (a) and crop yield (b) impacts associated with the decommissioning of coal-fired power units, and the geographical distributions of lives (c) and crops (d) saved. a,b, Estimates are shown for three models on the basis of their predictive power for pollution changes shown in Fig. 2. The plant location was used as the unit of analysis and each plant was matched to its county crop and demographic data (circles in $\mathbf{a}$ and $\mathbf{b}$; this is the total effect of shutdowns and is not normalized by the average number of units closed simultaneously). Information was aggregated about all of the plants within a $25 \mathrm{~km}$ (squares in a and $\mathbf{b}$ ) and $200 \mathrm{~km}$ (diamonds in $\mathbf{a}$ and $\mathbf{b}$ ) radius to the county level to match with county data. Using the more local $25 \mathrm{~km}$ estimate at the county level (squares in $\mathbf{a}$ and $\mathbf{b}$ ), the decommissioning of each coal-fired unit is associated with a $0.18 \%$ reduction $(0.01-0.35 \%)$ in overall mortality rate. When broken down by age group, these effects more strongly impact the $45-84$ age groups. Coal-unit shutdowns are also associated with an increase in corn yields of $1.1 \%(0.56-1.63 \%)$. All of the analyses include unit and year fixed effects to time-invariant location-specific factors as well as overall temporal shocks that might confound the relationship. The error bars show the 5\%-95\% CI on the basis of s.e. clustered at the location or county level. The distribution of these impacts (central estimate) is shown in $\mathbf{c}$ and $\mathbf{d}$ for $25 \mathrm{~km}$; crop impacts are statistically significant out to $200 \mathrm{~km}$ although mortality effects are not (200 km crop estimates are shown in Extended Data Fig. 9). Aggregating the more restricted local $25 \mathrm{~km}$ estimates suggests that the shift in feedstock away from coal saved $22,563(16,896-43,428)$ lives and 329 million (169-490 million) bushels of corn production. Aggregating the $200 \mathrm{~km}$ crop impacts raises the central estimates to 1.8 billion bushels saved by decommissioning of coal-fired units between 2005 and $2016^{1,37,74}$.

The Extended Data Fig. 4 caption has been updated to reflect the correct ordering of panels. The sentence '(a,c,e) As in Fig. 2b: Average near-surface (Planetary Boundary Layer) $\mathrm{SO}_{2}$, tropospheric $\mathrm{NO}_{2}$, and surface $\mathrm{O}_{3}$ surrounding operating electric power plants, by fuel type.' has been updated to:

'(a,c,e) As in Fig. 2b: Average surface $\mathrm{O}_{3}$, near-surface (Planetary boundary Layer) $\mathrm{SO}_{2}$, and tropospheric $\mathrm{NO}_{2}$ surrounding operating electric power plants, by fuel type.

Extended Data Fig. 5 and Extended Data Fig. 7 have been updated to reflect the correct unit-specific estimates. Extended Data Fig. 8 and Extended Data Fig. 9 have also been updated to reflect the correct unit-specific estimates (in Extended Data Fig. 9 the mortality estimates for $200 \mathrm{~km}$ were removed (as in Fig. 3), as estimates out to $200 \mathrm{~km}$ are not statistically significant). The captions for Extended Data Figs. 8 and 9 have been modified as follows:

In the Extended Data Fig. 8 caption, the text 'Surface $\mathrm{PM}_{2.5}$ estimates for corn are large and unstable (Supplementary Tables 7-9).' was added as a last sentence. In the Extended Data Fig. 9 caption, the text 'The left column shows the results presented in Fig. 3c-f, with mortality and crop yield impacts integrated over the study period for plants within (a) a $200 \mathrm{~km}$ radius, and (b) a $25 \mathrm{~km}$ radius from each county. Right column shows the calculation described for impacts of remaining coal-fired units still operating, assuming that their impacts are the same as those that have been decommissioned.' has been updated to:

'a, The left two panels are the same as Fig. $3 \mathrm{c}-\mathrm{d}$, showing mortality and crop yield impacts integrated over the study period for plants within $25 \mathrm{~km}$ from each county. The right column shows the calculation described for impacts of remaining coal-fired units still operating, assuming that their impacts are the same as those that have been decommissioned. $\mathbf{b}$, Corn yield impacts integrated over the study period for plants within $200 \mathrm{~km}$ from each county. As in a, the left panel shows the impacts of units shut down, and the right panel shows the estimated impacts of coal-fired units that remained in operation.'

Extended Data Fig. 10 has been updated to reflect the correct unit-specific estimates, and also the error bars were removed from the first and third bars as there is not a strict answer for the uncertainty of a ratio. The correction of the aggregation error resulted in an overall larger per- $\mu \mathrm{g} \mathrm{m}^{-3}$ estimate. In the Extended Data Fig. 10 caption, the text 'Central mortality estimates in this study are similar to previous empirical exposure studies, for both total mortality and infant mortality.' has been updated to:

'Central reduced-form mortality estimates in this study, converted to a per- $\mu \mathrm{g} \mathrm{m}^{-3}$ basis, are similar to previous empirical exposure studies, for both total mortality and infant mortality'

Additionally, the Supplementary Information file has been updated as follows: (1) in the Supplementary Methods, 'Total Impacts Calculations' subsection, the text has been updated to reflect updated figure numbering; (2) in the Supplementary Discussion, 'Comparison with Previous Studies' subsection, values and units have been updated; (3) in Supplementary Tables 2-6, values were updated; and (4) in Supplementary Tables 7-9, county numbers were updated.

All these errors have now been corrected. 

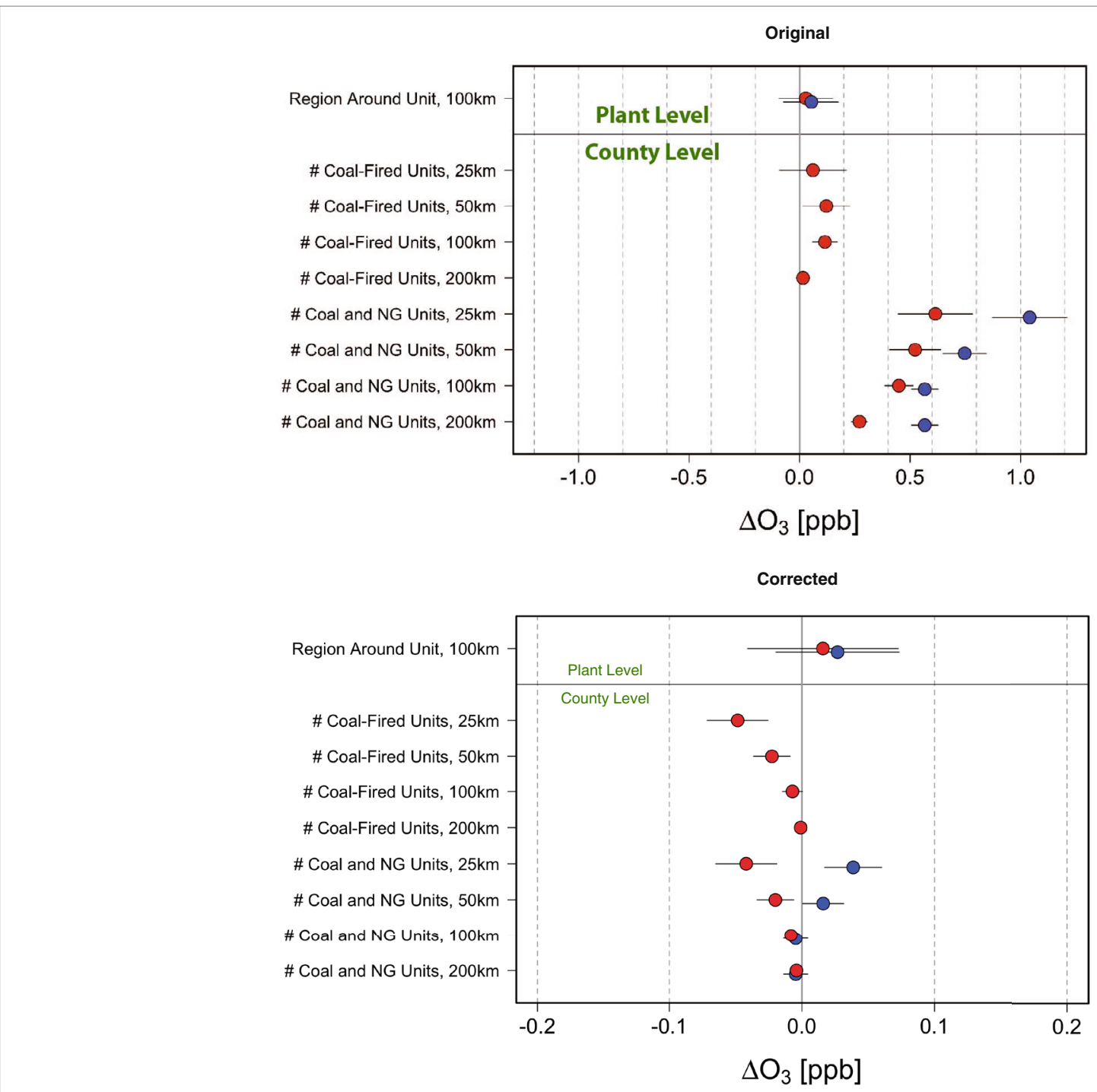

Extended Data Fig. 5 | Original and corrected. 
Original

a

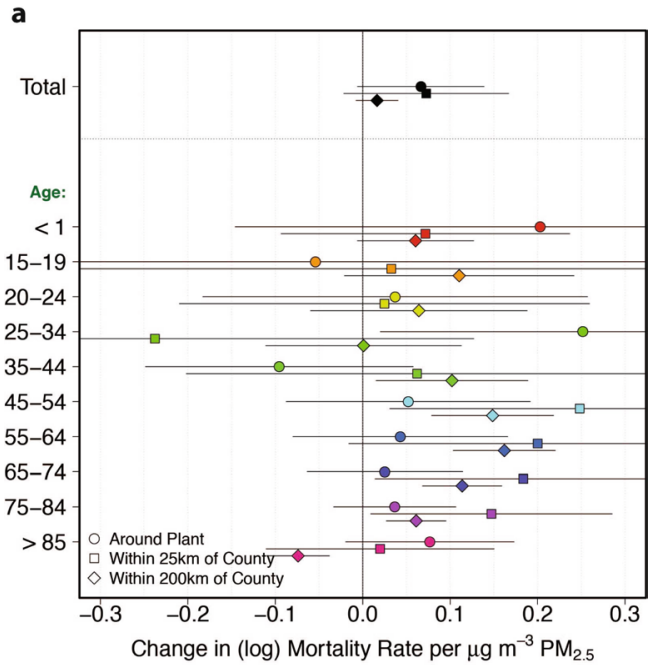

b

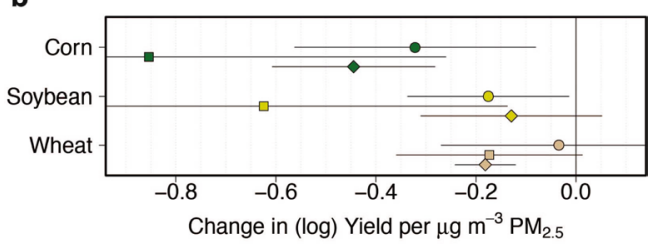

Corrected

a

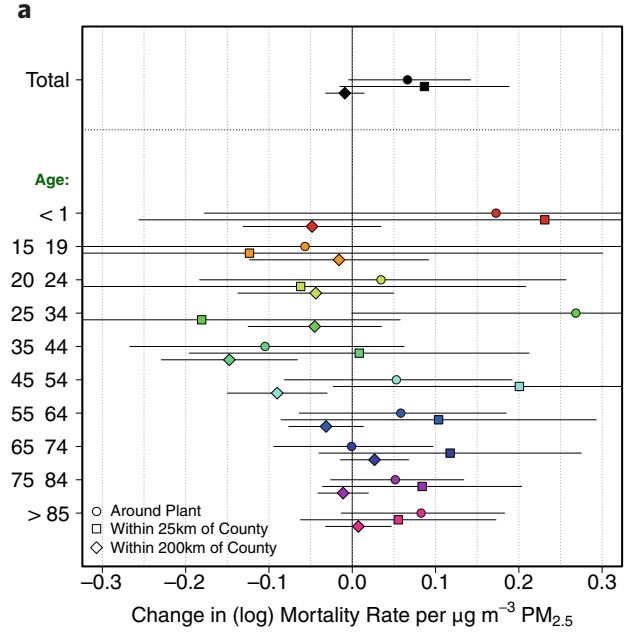

b

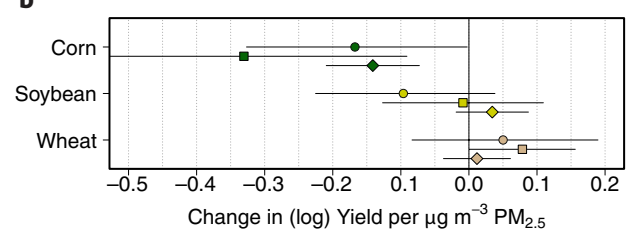

Extended Data Fig. 7 | Original and corrected. 


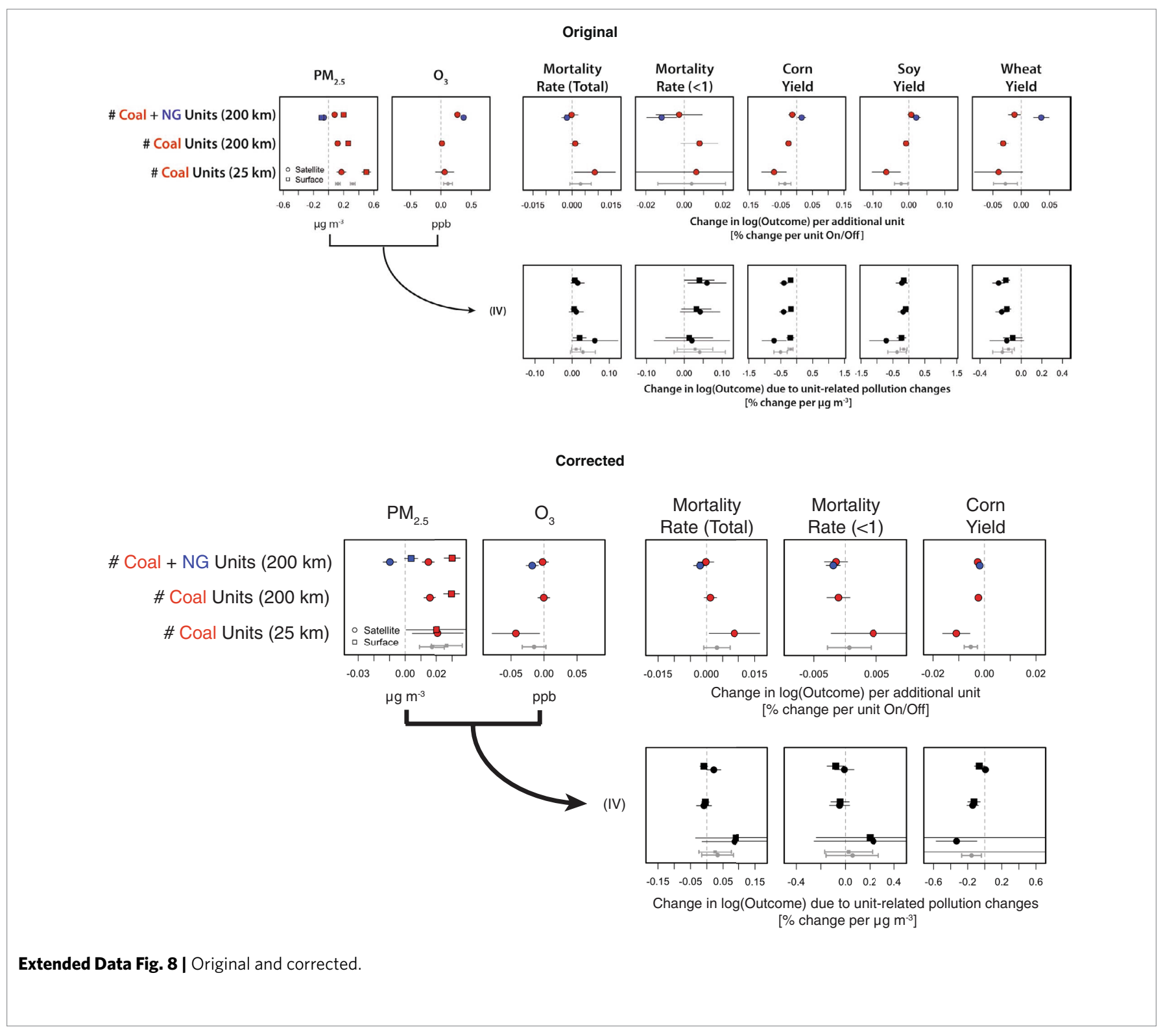




\section{Original}

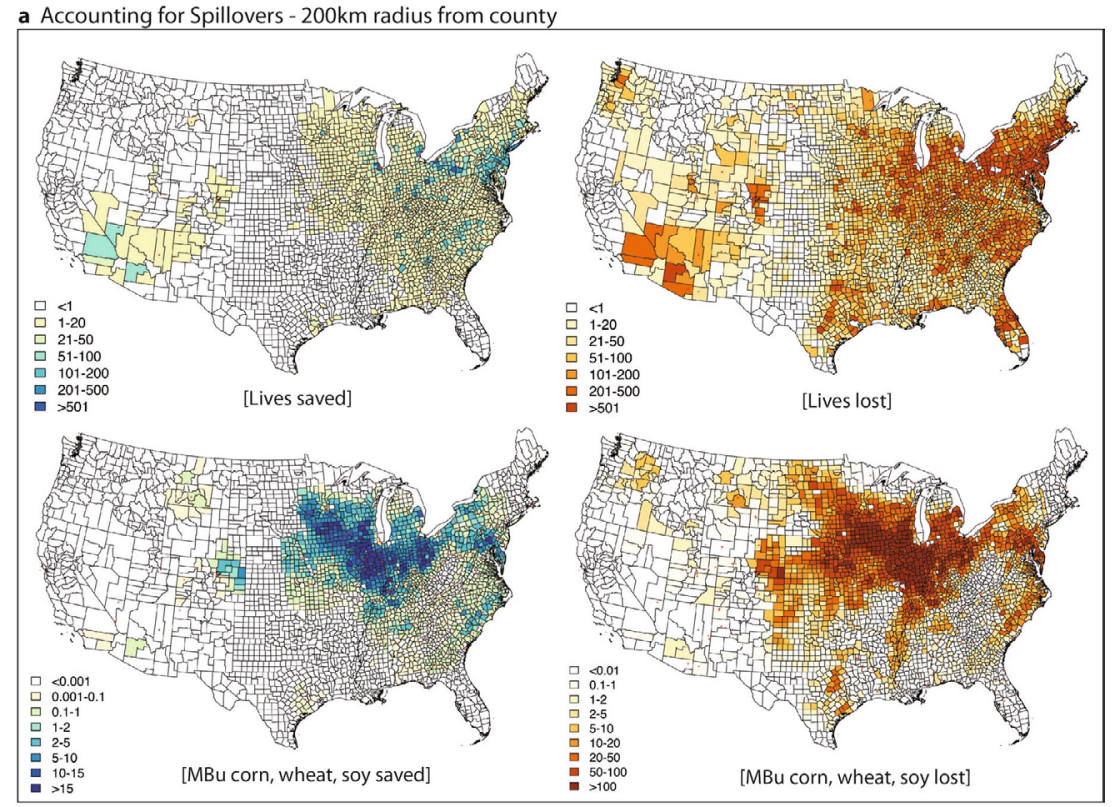

b Local Only - $25 \mathrm{~km}$ radius from county

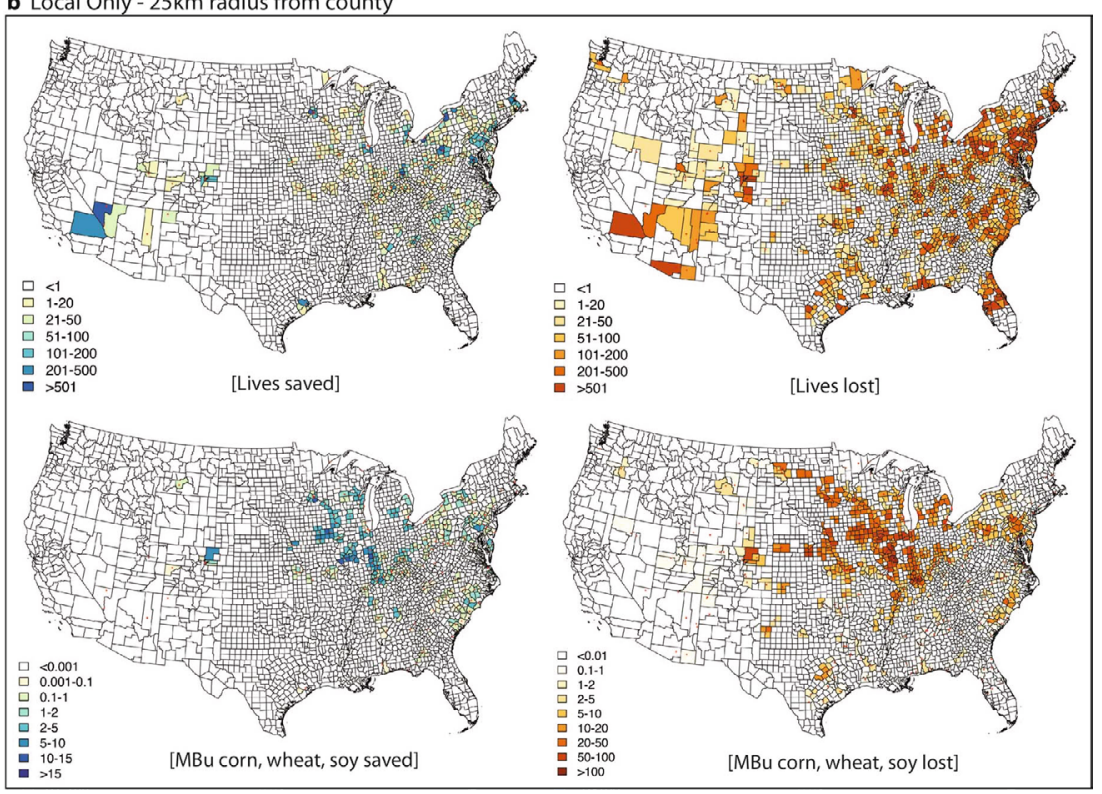

Extended Data Fig. 9 | Original. 


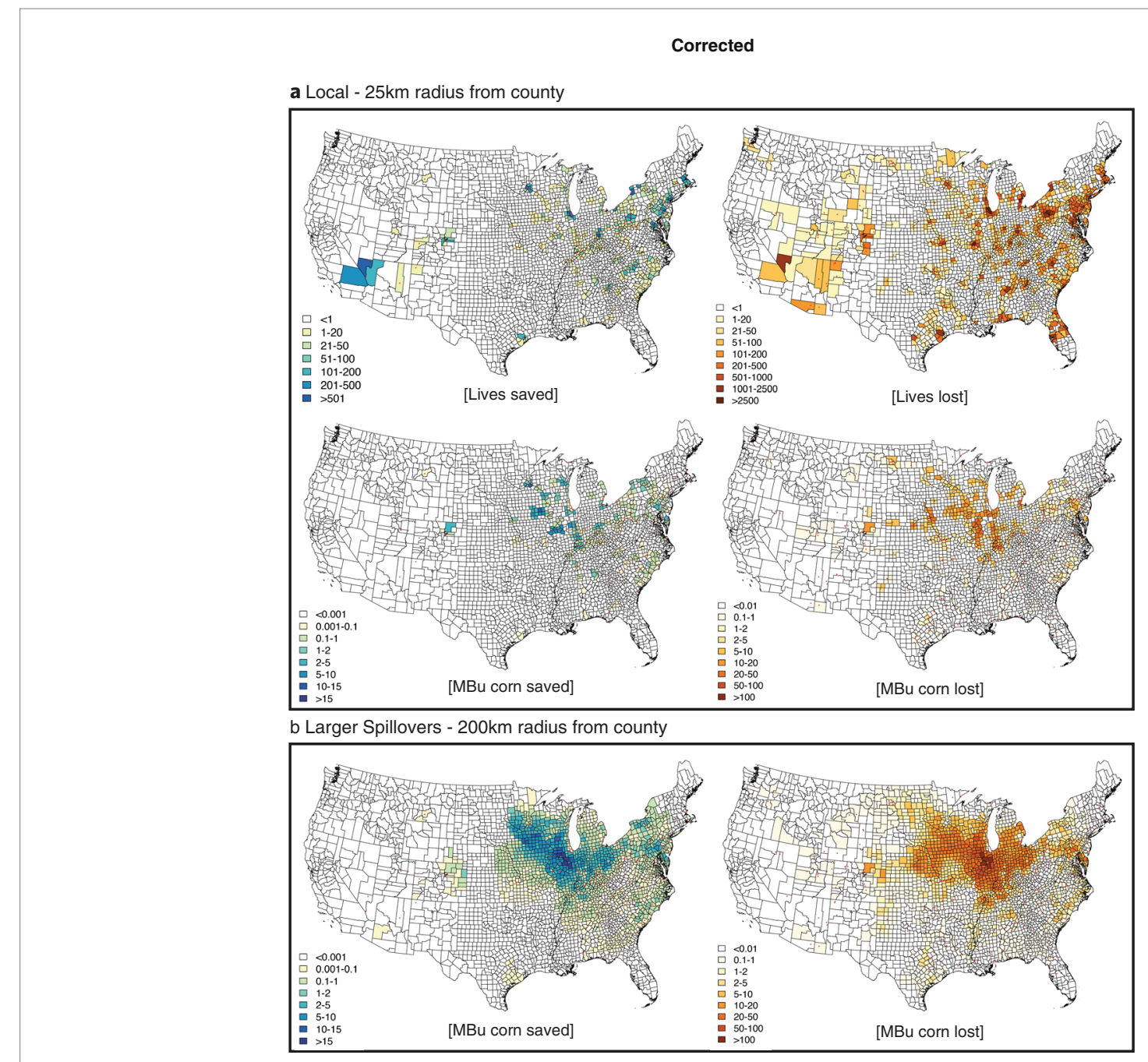

Extended Data Fig. 9 | Corrected. 
Original

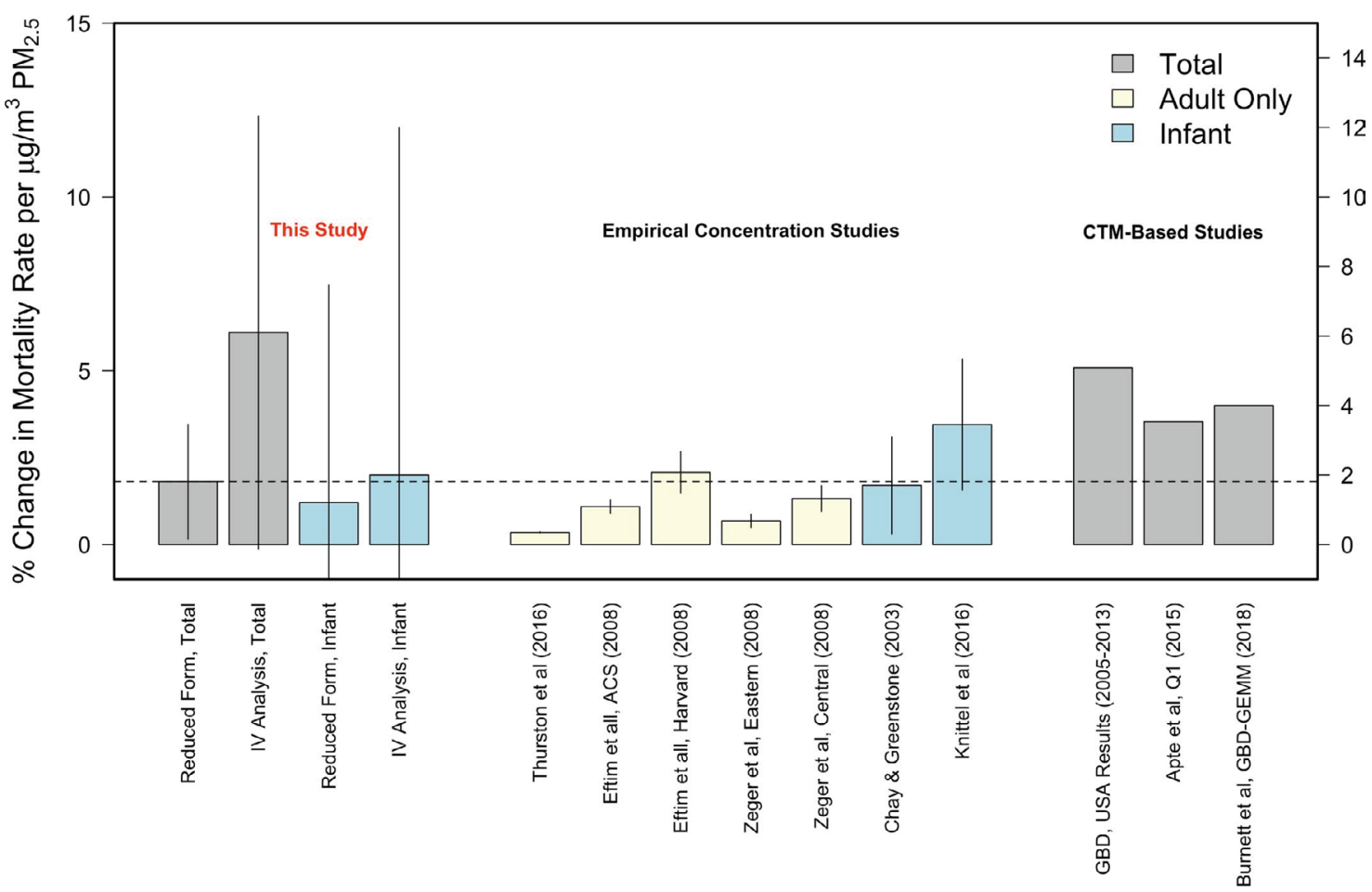

Corrected

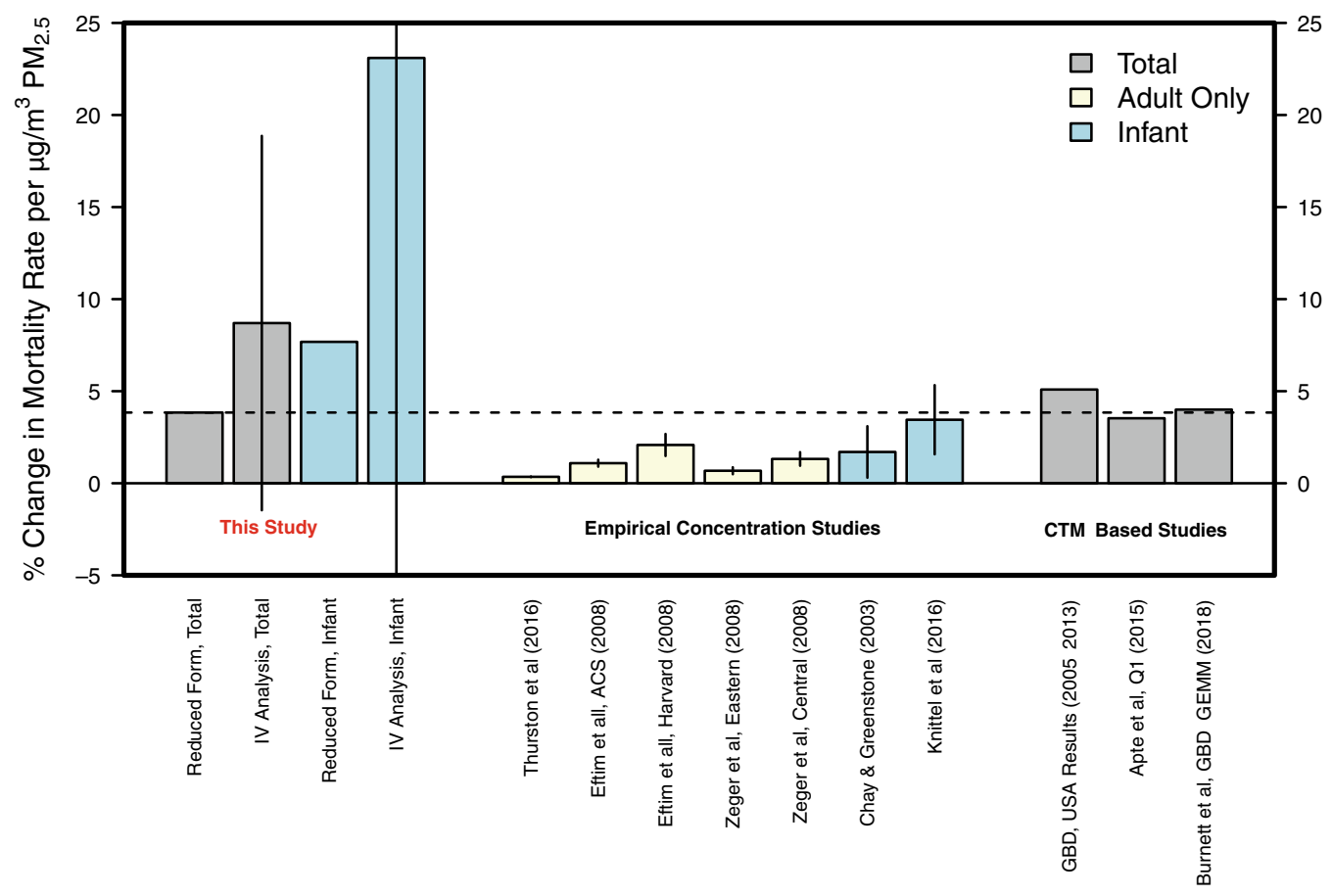

Extended Data Fig. 10 | Original and corrected.

Published online: 1 June 2020

https://doi.org/10.1038/s41893-020-0548-Z

(c) The Author(s), under exclusive licence to Springer Nature Limited 2020 